\section{Dr. Harth replies}

\section{To the Editor:}

First, let us get a little detail in perspective, before dealing with more momentous matters. Russell and Ferrari point out that the article by Karnezis, et $a l^{1}$, which I cited ${ }^{2}$, referred to Greek late whiplash sufferers who were all litigants — that is a highly selected group so "that generalizing their findings to the clinical population is impossible". Quite right. The reason for citing it was that in an article, coauthored by Ferrari, the readers were informed, at some length, that in Greece chronic disease was recognized, psychosocial factors were deemed to be relevant, insurance disability was available, and litigation occurred, but the outcome of whiplash was so benign as to render late whiplash almost nonexistent ${ }^{3}$. I sadly pointed out that even in that country there appeared to be many unhappy campers.

However, let me hasten to admit that Russell and Ferrari and I agree on many things: yes, many studies, perhaps all, have flaws; yes "medical science advances, our capacity to manage complex medical problems advances..."; yes, "progress requires...new ideas to be explored". The truth be told, I believe that Russell, Ferrari, and I would also accept other important philosophical concepts such as "only God can grow a tree," or "a dog is a man's best friend."

Where I hesitate to follow my 2 colleagues is in their belief that the greater the number of flawed studies (they all are, we just agreed), the better (after all, who can wait for unattainable perfection). This is what they presumably like to call the Tukeyan approach. The reference is obscure, but I assume that they are thinking of the statistician John Tukey who opined that an approximate answer to the right question was better than an exact answer to the wrong question. Well, maybe. And, maybe, given enough monkeys and enough typewriters...
I am puzzled, as are many, by the high incidence of late whiplash. Perhaps social and cultural factors are at work ${ }^{4}$. Those are important considerations. That also means that it is equally important to apply appropriate scientific methodology for their study and assessment. That is what I tried to convey ${ }^{2}$; as for the available evidence, I am afraid that we ain't there yet.

MANFRED HARTH, MD, FRCPC, Emeritus Professor of Medicine, Division of Rheumatology, University of Western Ontario, London, Ontario, Canada. Address reprint requests to Dr. M. Harth, AIM Health Group, 140 Oxford Street East, Suite 300, London, Ontario N6A 5R9.

\section{REFERENCES}

1. Karnezis IA, Drosos GI, Kazakos KI. Factors affecting the timing of recovery from whiplash neck injuries: study of a cohort of 134 patients pursuing litigation. Arch Orthop Trauma Surg 2007;127:633-6.

2. Harth M. Stopping late whiplash: which way to utopia? [editorial]. J Rheumatol 2008;35:2303-5.

3. Partheni M, Constantoyannis C, Ferrari R, Nikiforidis G, Voulgaris S, Papadakis N. A prospective cohort study of the outcome of acute whiplash injury in Greece. Clin Exp Rheumatol 2000;18:67-70.

4. Russell AS, Ferrari AS. Whiplash: social interventions and solutions [editorial]. J Rheumatol 2008;35:2300-2.

J Rheumatol 2009;36:6; doi:10.3899/jrheum.090021 